\title{
PROBLEMS OF EMERGENCY ADMISSIONS TO LONDON HOSPITALS*
}

\author{
BY \\ M. D. WARREN, JANE COOPER, AND JOAN L. WARREN \\ Public Health Department, London School of Hygiene and Tropical Medicine
}

Difficulty in admitting or failure to admit patients considered to be in urgent need of care and treatment in hospital are frustrating experiences for general practitioners and disquietening and perplexing ones for patients and their relatives. Such episodes are likely to undermine confidence in the organization and administration of the health services. They are, therefore, worthy of detailed study. Previous surveys have shown that delay in hospital admissions is a common complaint among general practitioners (Cartwright, 1964; Cartwright and Marshall, 1965) and that difficulty of admission has been associated particularly with older patients (Gibson, Hughes, and Broughton, 1958) and with maternity cases in London. This last problem has been eased by administrative changes introduced during 1964 (Ministry of Health, 1965) and is not considered in this paper.

The study described in this paper followed up all those patients who had been referred with an urgent request for hospital admission to the Emergency Bed Service (EBS) in London during a period of 12 months, but for whom no arrangement could be made for admission at the time of the referral. By comparing this group of patients with groups who were admitted at the time of referral, the influence of age, sex, diagnosis, location, and other factors on the probability of successful emergency admission has been examined. On the basis of the data obtained, suggestions are made about the organization of domiciliary and hospital services.

\section{EBS PROCEDURE}

\section{MethodS}

This study was based entirely on patients referred to the EBS; it is, therefore, necessary to describe briefly the EBS procedure. (For full descriptions of

* This study was supported by a research grant from the Ministry of Health. procedures for emergency admissions, see Abercrombie, 1956, 1961.) Any general practitioner in the Greater London area requiring the immediate admission to hospital of a patient suffering from an acute medical or surgical condition (other than accidents) may telephone the EBS and give full details of the case to one of the "Operation Room" staff. The EBS staff then contact hospitals and try to arrange the admission of the patient. Frequently the referring doctor has already tried to arrange the admission of his patient to his local hospital before seeking the help of the EBS. The EBS does not arrange admission for patients with acute psychiatric conditions; these are dealt with by the health departments of the Greater London Boroughs. The EBS accepts maternity cases and cases of infectious disease (other than tuberculosis) but this study was not concerned with these groups of patients. During each of the last 5 years the total number of applications for admission has been between 55,000 and 61,000 . In all, it is estimated that one-fifth of all emergency admissions in the Greater London area are made through the EBS (Abercrombie, 1959).

If the EBS Operation Room staff are unable to find a hospital bed for a case, the details of the case are submitted to the Regional Medical Admissions Officer (RMAO) on duty at the EBS headquarters. The RMAO may tell the staff to submit the details of the case to the medical referee, a doctor nominated by the hospital management committee, nearest to the patient's address-the procedure referred to in this paper as "Medical Refereeing" (MR). Alternatively, in less urgent cases, the RMAO may discuss the details of the case with the referring doctor and suggest that he either holds the case overnight and applies again next day, seeks a domiciliary consultation, arranges for the patient to be seen that day in the Out-Patient Department of a hospital, or takes some other action. This procedure is referred to as "Referral Back" (RB) (Abercrombie, 1956). 
SURVeY Procedure

Details of all patients referred back by the EBS to their general practitioners between April 1, 1965, and March,31, 1966, were obtained from the EBS records. Similar details of every tenth patient admitted through the medical referee procedure(MR cases) and every fiftieth patient admitted through the normal procedure (controls) were recorded. The count in each case was taken seriatim, having started from a random number. All the basic information was collected within 4 days of the occurrence of the event and recorded on a standard form. A letter was sent to the general practitioner of each of the RB cases, asking him to complete a short questionnaire. If this was not returned within one week, a second letter and form were sent to him. On a few occasions a third letter had to be sent, and very exceptionally a fourth. This procedure was tried out for 6 weeks in a pilot survey and found to be satisfactory.

\section{RESULTS}

During the 12 months of the survey, the EBS arranged for the admission of 46,600 general patients by direct contact with hospitals, and of 7,024 patients through the medical referee procedure. Only 395 patients had to be referred back to their general practitioners (King Edward's Hospital Fund, 1966).

Table I shows these numbers and those in each category in the study, on which the analyses have been based. Of the 395 patients referred back, five were being referred back for the second time in relation to the same episode of illness and were therefore duplicate cases. Three patients were referred back to a Deputizing Service and the name of the general practitioner was not known, so that followup was not possible. For the 387 remaining patients, replies were received from 371 doctors (96 per cent.). It was possible to obtain information from EBS data regarding another seven patients, so that some follow-up information is available in regard to 378 (98 per cent.).

TABLE I

NUMBERS OF PATIENTS IN EACH CATEGORY IN THE STUDY

\begin{tabular}{c|c|c|c|c}
\hline Category & $\begin{array}{c}\text { Total No. } \\
\text { dealt with } \\
\text { by EBS }\end{array}$ & $\begin{array}{c}\text { No. in } \\
\text { Sample }\end{array}$ & $\begin{array}{c}\text { Sample as } \\
\text { Percentage } \\
\text { of Total }\end{array}$ & $\begin{array}{c}\text { No. of } \\
\text { Replies }\end{array}$ \\
\hline $\begin{array}{c}\text { Direct Admissions } \\
\text { (Controls) }\end{array}$ & 46,600 & 935 & 2 & - \\
$\begin{array}{c}\text { Medical Referee } \\
\text { Admissions } \\
\text { (MR) }\end{array}$ & 7,024 & 702 & 10 & - \\
$\begin{array}{c}\text { Patients referred } \\
\text { back to GPs } \\
\text { (RB) }\end{array}$ & 395 & 395 & 100 & 371 \\
\hline
\end{tabular}

\section{Factors AfFecting Emergency Admissions}

In a conurbation with a large number of hospitals, $\frac{1}{\mathbb{1}}$ a central admitting organization for emergency? admissions can detect factors relating either to the $\overrightarrow{\vec{F}}$ patients or the medical services that facilitate or impede admission. The probable factors are the sex, $\frac{\bar{O}}{-}$ age, and diagnosis of the patient, his area of residence, $\overline{\bar{c}}$. the month and time of day when the admission is $\vec{\nabla}$ sought and, perhaps, some personal or professional $\varrho$ features of the patient's general practitioner (for $\%$ example, his personal relations with the staff of the $\vec{\circ}$ local hospital). These factors are examined below.

In this study three groups of patients are con- $\vec{\omega}$ sidered:

(1) "Controls".-These patients were admitted to $\stackrel{\circ}{\circ}$ hospital through the normal procedure of the EBS;

(2) "MR Cases".-These were admitted through + the medical refereeing procedure and therefore $\vec{A}$ difficulty in obtaining admission was experienced by $\overrightarrow{\text { O }}$ the EBS;

(3) "RB Cases".-These patients were referred $\vec{O}$ back to the general practitioner.

Two measures may be used as indicators of difficulty of admission. The first is the proportion of all cases that fall in the MR and RB categories-@sc this proportion rises, more difficulty is being expes. enced. In calculating these rates from the dapaio collected, allowance has to be made for the different? proportions used in sampling the groups of patients. The second measure is the average number of hospitals approached by the EBS before admission $\cong$ is achieved, and this, naturally, only uses the first two categories.

Sex and Age of Patients.-Table II shows the number of men and women in each of the three

TABLE II

SURVEY PATIENTS, BY SEX AND AGE GROUP

\begin{tabular}{|c|c|c|c|c|c|c|c|}
\hline \multirow{2}{*}{ Sex } & \multirow{2}{*}{ Age Group } & \multicolumn{2}{|c|}{ Controls } & \multicolumn{2}{|c|}{ MR Cases } & \multicolumn{2}{|c|}{ RR Cases } \\
\hline & & No. & Per cent. & No. & Per cent. & No. & Per cent. $₹$ \\
\hline \multirow[t]{2}{*}{ Male } & $\begin{array}{l}0- \\
15- \\
45- \\
65- \\
75-\end{array}$ & $\begin{array}{r}69 \\
75 \\
116 \\
75 \\
72\end{array}$ & $\begin{array}{l}17 \\
18 \\
29 \\
18 \\
18\end{array}$ & $\begin{array}{r}3 \\
18 \\
68 \\
85 \\
88\end{array}$ & $\begin{array}{r}1 \\
7 \\
26 \\
32 \\
34\end{array}$ & $\begin{array}{r}0 \\
8 \\
34 \\
43 \\
61\end{array}$ & $\begin{array}{r}5 \\
23 \\
30 \\
42\end{array}$ \\
\hline & Total & 407 & 100 & 262 & 100 & 146 & 100 \\
\hline \multirow[t]{2}{*}{ Female } & $\begin{array}{l}0- \\
15- \\
45- \\
65- \\
75-\end{array}$ & $\begin{array}{r}55 \\
209 \\
94 \\
79 \\
91\end{array}$ & $\begin{array}{l}10 \\
40 \\
18 \\
15 \\
17\end{array}$ & $\begin{array}{r}3 \\
113 \\
65 \\
109 \\
150\end{array}$ & $\begin{array}{r}1 \\
25 \\
15 \\
25 \\
34\end{array}$ & $\begin{array}{r}0 \\
28 \\
38 \\
54 \\
129\end{array}$ & $\begin{array}{l}11 \\
15 \\
22 \\
52\end{array}$ \\
\hline & Total & 528 & 100 & 440 & 100 & 249 & 100 \\
\hline \multicolumn{2}{|c|}{ Total (Both Sexes) } & 935 & - & 702 & - & 395 & - \\
\hline \multicolumn{2}{|c|}{$\begin{array}{l}\text { Percentage of Total .. } \\
\text { who are Female }\end{array}$} & & 56 & & 63 & & 63 \\
\hline
\end{tabular}


groups. There is a higher percentage of women in the MR and RB groups, showing that there is more difficulty in obtaining an emergency admission for a female patient than for a male. This is confirmed by the use of the other measures (Table III). $11 \cdot 3$ per cent. of admissions of males were made via the MR procedure compared to $14 \cdot 2$ per cent. of admissions of females $(P<0.001)$. The percentages of males and females that cannot be admitted at the time of referral are 0.6 and 0.8 per cent. respectively $(P<0.05)$. The average number of hospitals approached before successful admission is achieved was 3.0 for males and 3.2 for females. This disadvantage to the women is associated with age, for there are, of course, more elderly women in the population than elderly men.

TABLE III

EFFECT OF AGE ON EMERGENCY ADMISSIONS

\begin{tabular}{|c|c|c|c|c|c|c|}
\hline \multirow{2}{*}{$\underset{\text { Group }}{\text { Age }}$} & \multicolumn{2}{|c|}{$\begin{array}{c}\text { Percentage } \\
\text { Admissions via MR } \\
\text { procedure }\end{array}$} & \multicolumn{2}{|c|}{$\begin{array}{l}\text { Per cent. } \\
\text { Referred Back }\end{array}$} & \multicolumn{2}{|c|}{$\begin{array}{l}\text { Average No. of } \\
\text { Hospitals } \\
\text { Approached }\end{array}$} \\
\hline & Male & Female & Male & Female & Male & Female \\
\hline $\begin{array}{c}0- \\
15- \\
65- \\
75-\end{array}$ & $\begin{array}{r}0.9 \\
8 \cdot 2 \\
18 \cdot 3 \\
19 \cdot 4\end{array}$ & $\begin{array}{r}1 \cdot 1 \\
10 \cdot 5 \\
21 \cdot 4 \\
24 \cdot 3\end{array}$ & $\begin{array}{l}0 \\
0 \cdot 4 \\
0 \cdot 9 \\
1 \cdot 3\end{array}$ & $\begin{array}{l}0 \\
0 \cdot 4 \\
1 \cdot 1 \\
2 \cdot 1\end{array}$ & $\begin{array}{l}2 \cdot 3 \\
2 \cdot 8 \\
3 \cdot 1 \\
3 \cdot 6\end{array}$ & $\begin{array}{l}2 \cdot 0 \\
2 \cdot 8 \\
3 \cdot 7 \\
4 \cdot 1\end{array}$ \\
\hline $\begin{array}{l}\text { All } \\
\text { Ages }\end{array}$ & $11 \cdot 3$ & $14 \cdot 2$ & 0.6 & 0.8 & $3 \cdot 0$ & $3 \cdot 2$ \\
\hline
\end{tabular}

Of the men in the control group, 36 per cent. are aged 65 years or more, and this percentage rises to 66 in the MR group and 72 in the RB group. For the women the percentages are very similar: 32,59 , and 74 per cent. respectively. Similarly, it is found that, whereas 11.3 per cent. of all admissions of males are made through the MR procedure, the equivalent figure is $18 \cdot 3$ per cent. for those aged between 65 and 74 and 19.4 per cent. for those over the age of 74 years. For women the percentages are $14 \cdot 2,21 \cdot 4$, and $24 \cdot 3$ respectively. The proportion of patients who are not admitted also rises with age, from 0.4 per cent. for men and women between the ages of 15 and 64 years to $1 \cdot 3$ per cent. for men and $2 \cdot 1$ per cent. for women over the age of 74 years. Fig. 1 shows the consistent increase in the average number of hospitals approached with rising age of the patient for whom admission is sought. (In calculating these figures, women with a presenting diagnosis of abortion have been excluded.) The difference between the averages of the number of hospitals approached for patients under the age of 65 years and for those aged 65 or above is statistically significant $(P<0.001)$.

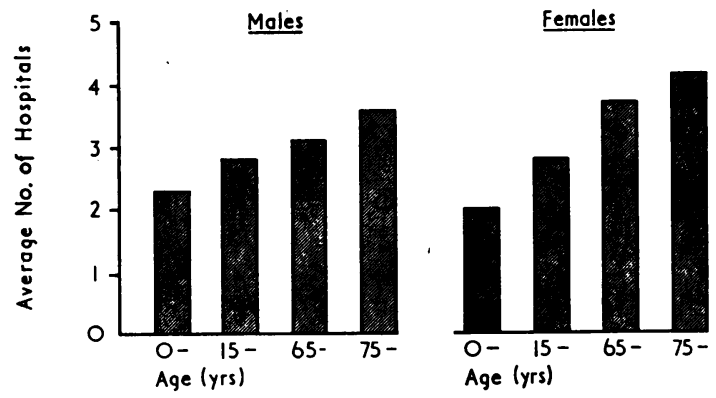

FIG. 1.-Average number of hospitals approached by EBS before patient is admitted, shown by age group for each sex; includes all diagnostic categories except abortions.

DiAGNOSIs.-The provisional diagnosis is obviously an important determinant in admission, and is likely to be associated with age. Table IV shows the eight commonest diagnoses or groups of diagnoses in each of the three categories of patients. The diagnoses analysed were those stated by the general practitioner to the EBS staff; they were classified, using the definitions of the International Classification of

TABLE IV

COMMONEST DIAGNOSES, BY CATEGORY OF PATIENTS

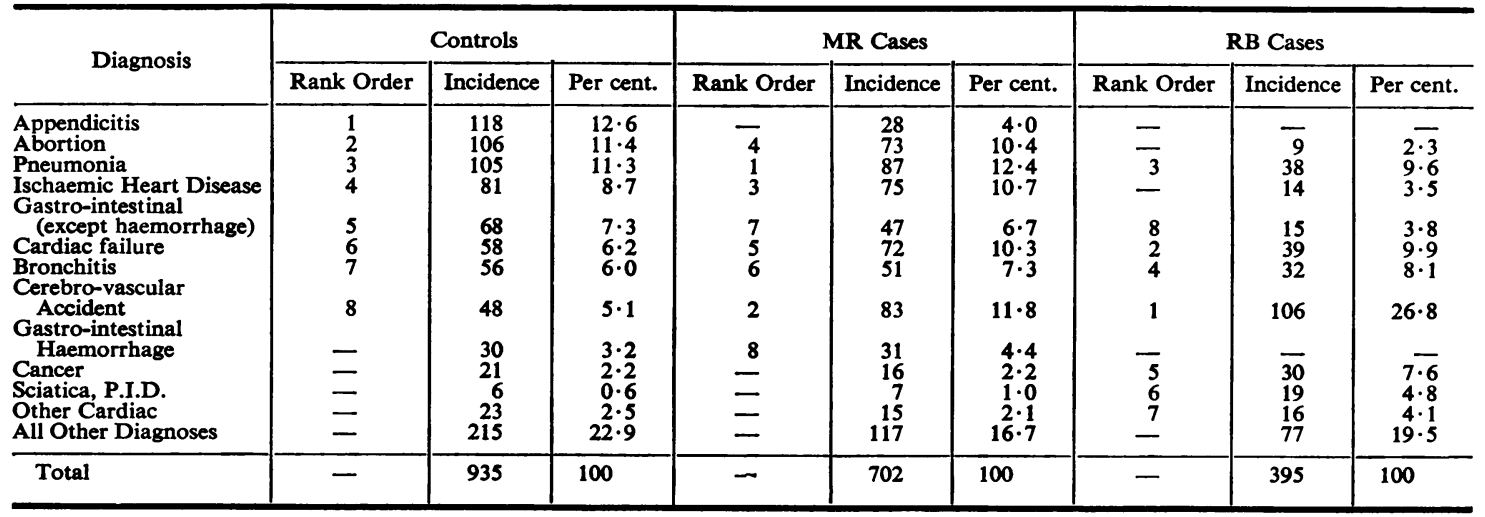


Diseases, into 28 categories that seemed, as a result of the pilot study, to be of particular interest. The commonest diagnoses given among the "controls" were appendicitis and abortion which together account for over one in every five of these admissions. Abortions also account for 10 per cent. of the MR cases, so that this study confirms the difficulty experienced by the EBS in obtaining admission for patients with this condition (see King Edward's Hospital Fund, 1965). Cerebro-vascular accident is by far the commonest diagnosis among the referred-back cases, accounting for almost 27 per cent.; among the medical-refereed cases, this diagnosis is the second commonest, accounting for nearly 12 per cent. Cardiac failure, pneumonia, and bronchitis are the next commonest diagnoses in the RB cases, followed by cancer and sciatica and prolapsed intervertebral disk. Clearly all these diagnoses, except the last, are commoner among older people. The cerebro-vascular accidents, cancer, and sciatica (presumably severe) have in common a need for heavy nursing care. Some of these diagnoses may not suggest urgency, but usually the condition was of very recent onset or there had been an acute exacerbation or deterioration.

Diagnosis and age are linked. But it is possible by considering patients with the same diagnosis to isolate the effect of age on probability of admission. The four diagnostic categories, cerebro-vascular accident, pneumonia, cardiac failure, and bronchitis, containing 237, 230,169, and 139 patients respectively, were large enough for such analysis. $6 \cdot 3$ per cent. of patients aged less than 65 years with pneumonia were admitted through the MR procedure, whereas the proportion is $22 \cdot 3$ per cent. for the older patients; for bronchitis the figures were similar $-7 \cdot 4$ and $25 \cdot 7$ per cent. For cardiac failure and cerebrovascular accident about 20 per cent. of all patients in each age group were admitted through the MR system. Fig. 2 shows the percentage of all patients in each of the diagnostic and survey categories who were aged 65 years or more. There is a considerable increase in the percentage of older people in the groups experiencing difficulty in admission in the

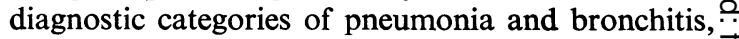
some increase in those with cerebro-vascular acci- $\overrightarrow{\vec{S}}$ dent, but no such increase in those with cardiac $-{ }_{0}^{-}$ failure. This suggests that patients with diagnoses of $\frac{}{\circ}$ cardiac failure or cerebro-vascular accident experi- $\frac{\bar{\sigma}}{\bar{\alpha}}$ ence difficulty of admission regardless of age.

Locality of Patient's Residence.-The address ${ }^{\infty}$ at which the patient was living at the time of referral $\vec{O}$ to the EBS was noted. It is therefore possible to see $\overrightarrow{-}$ the distribution of requests by regional hospital ${ }_{\sigma}^{\omega}$ board (R.H.B.) area and by borough, regardless of $\bar{\alpha}$ where the patient was finally admitted. In other $\frac{\rho}{5}$ words, the areas of maximum demand on the EBSi can be identified. During the year under review, the $\overrightarrow{+}$ percentage distribution of all requests investigated $\vec{A}$ (regardless of outcome) was as follows:

North-West Metropolitan R.H.B.-32 per cent. North-East Metropolitan R.H.B.-29 per cent. South-East Metropolitan R.H.B.-21 per cent. South-West Metropolitan R.H.B.-18 per cent.

Because of varying local admission arrangements a of different procedures adopted by general praftitioners, the size of the population served by teo EBS in each of the R.H.B. areas is not known, so that these figures, by themselves, cannot indicate $\overline{0}$ whether there is disproportionate usage in any area. Using the percentage of cases admitted through the medical referee procedure as an indicator of diffi- $\overrightarrow{0}$ culty, it is found that the North-East Metropolitan 3 R.H.B. had the highest figure at $16 \cdot 2$ per cent. and the South-East the lowest at 8 per cent. The percent-0 age of cases referred back was also highest in the North-East and lowest in the South-East (see Table V, $\stackrel{\odot}{\Im}$ opposite).

As regards boroughs, Barking, Havering, andô Redbridge in the North-East region and Ealing and $₹$

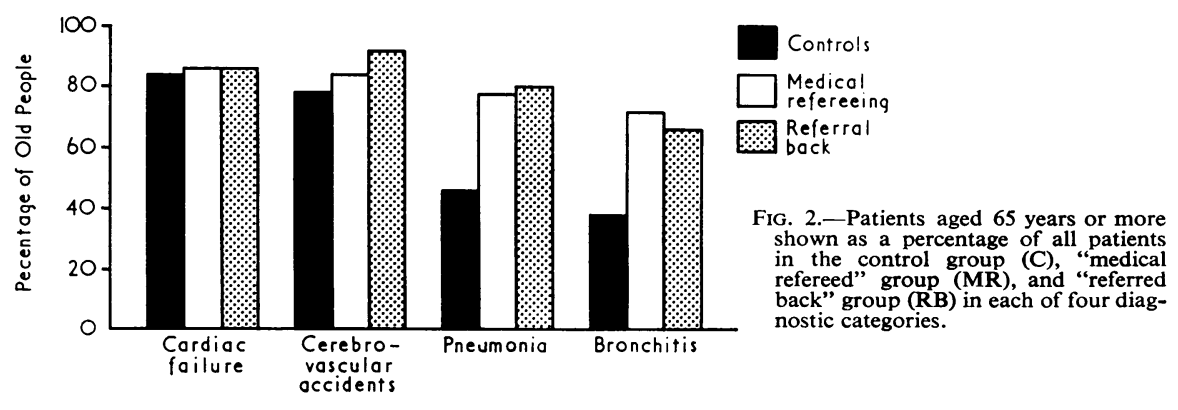


TABLE V

DISTRIBUTION OF PATIENTS BY REGIONAL HOSPITAL BOARD AREAS

\begin{tabular}{|c|c|c|c|c|c|}
\hline $\begin{array}{l}\text { Metropolitan } \\
\text { R.H.B. Area }\end{array}$ & $\begin{array}{c}\text { Controls } \\
\text { (1:50 } \\
\text { sample) }\end{array}$ & $\begin{array}{c}\text { MR } \\
(1: 10 \\
\text { sample })\end{array}$ & RB & $\begin{array}{c}\text { Percentage } \\
\text { MR } \\
\text { (corrected) }\end{array}$ & $\begin{array}{c}\text { Percentage } \\
\text { RB } \\
\text { (corrécted) }\end{array}$ \\
\hline $\begin{array}{l}\text { N.W. } \\
\text { N.E. } \\
\text { S.E. } \\
\text { S.W. }\end{array}$ & $\begin{array}{l}295 \\
265 \\
202 \\
173\end{array}$ & $\begin{array}{r}234 \\
259 \\
89 \\
120\end{array}$ & $\begin{array}{r}114 \\
132 \\
68 \\
81\end{array}$ & $\begin{array}{r}13 \cdot 6 \\
16 \cdot 2 \\
8 \cdot 0 \\
12 \cdot 1\end{array}$ & $\begin{array}{l}0.7 \\
0.8 \\
0.6 \\
0.8\end{array}$ \\
\hline Totals & 935 & 702 & 395 & $13 \cdot 0$ & 0.7 \\
\hline
\end{tabular}

Hounslow in the North-West all had medical referee rates of over 20 per cent. (that is one in every four to five admissions of patients from those boroughs admitted through the EBS had to be referred to the medical referee). Three of these boroughs also had above average percentages of patients referred back. Other boroughs from which there was a significant number of admissions with an above-average proportion of MR cases were Croydon, Merton, Harrow, Newham, and Westminster. The average MR rate for all the boroughs was 13.0 per cent. The boroughs with the most residents referred to the EBS were, in rank order, Newham, Southwark, Islington, Greenwich, Wandsworth, Waltham Forest, and Ealing. Those with fewest residents referred were Kingston, Richmond-on-Thames, Hillingdon, and Enfield.

TIME OF YeAR.-It has been the general experience of the EBS that the number of applications rises in January, February, and March of each year and during those months the proportion of admissions through the referee procedure also rises (Abercrombie, 1951, 1956). These findings were manifest during the year under investigation; $12 \cdot 1$ per cent. of all applications investigated occurred during January, $10 \cdot 3$ per cent. in February, and the same proportion in March. Only 6.4 per cent. occurred in July and in August. The major cause of the additional demand for hospital admissions in the first quarter of the year was the increase in the number of patients with acute respiratory disease; there was, also, an increased demand for admission of patients with ischaemic heart disease, cardiac failure, and cerebro-vascular accident. The result of this increased pressure on available hospital beds was an aggravation of the selecting factors already discussed. During the winter months the proportion of older people with respiratory disease and of patients with cardiac failure and cerebro-vascular accident who were not initially admitted rose.

TIME OF DAY.-About 30 per cent. of all patients were referred to the EBS between mid-day and 4.0 p.m., 20 per cent. within the preceding 4 hours, and another 20 per cent. in the subsequent 4 hours. Thus 70 per cent. of referrals were made between $8.0 \mathrm{a} . \mathrm{m}$. and 8.0 p.m. 75 per cent. of the cases subsequently admitted through the MR procedure and 91 per cent. of the RB cases were first referred to the EBS between 8.0 a.m. and 8.0 p.m. (Table VI). Only 10 per cent. of the MR cases and less than 1 per cent. of the RB cases occurred between midnight and 8.0 a.m. The highest proportion of applicants admitted through the MR procedure or referred back occurred between mid-day and 8.0 p.m. Two comments can be made on these findings. Firstly, during the small hours of the morning the hospitals probably play for safety and tend to admit rather than refuse patients and there is also a strong probability that more of the patients referred at that time are in more urgent need of admission than at other times. Secondly, as Fig. 3 shows, the vast majority of referrals back occur

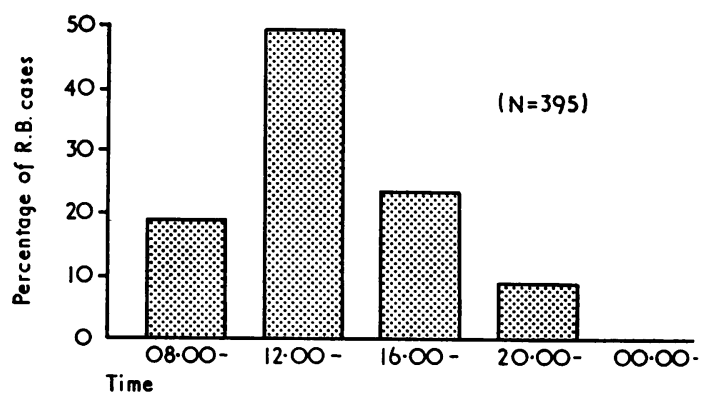

FIG. 3.-Time of day that "referred back" cases were initially referred to the EBS.

TABLE VI

TIME OF REFERRAL OF CASES

\begin{tabular}{|c|c|c|c|c|c|c|c|c|}
\hline \multirow{2}{*}{ Time of } & \multicolumn{2}{|c|}{ Controls 1: 50 sample } & \multicolumn{2}{|c|}{ MR Cases $1: 10$ sample } & \multicolumn{2}{|c|}{ RB Cases Complete } & \multirow{2}{*}{$\begin{array}{l}\text { MR Per cent. } \\
\text { (corrected) }\end{array}$} & \multirow{2}{*}{$\begin{array}{l}\text { RB Per cent. } \\
\text { (corrected) }\end{array}$} \\
\hline & No. & Per cent. & No. & Per cent. & No. & Per cent. & & \\
\hline $\begin{array}{l}00.00 \\
04.00 \\
08.00 \\
12.00 \\
16.00 \\
20.00\end{array}$ & $\begin{array}{r}82 \\
39 \\
197 \\
284 \\
187 \\
146\end{array}$ & $\begin{array}{r}9 \\
4 \\
21 \\
30 \\
20 \\
16\end{array}$ & $\begin{array}{r}52 \\
20 \\
137 \\
235 \\
155 \\
103\end{array}$ & $\begin{array}{r}7 \\
3 \\
20 \\
33 \\
22 \\
15\end{array}$ & $\begin{array}{r}1 \\
1 \\
73 \\
195 \\
89 \\
36\end{array}$ & $\begin{array}{l}- \\
19 \\
49 \\
23 \\
9\end{array}$ & $\begin{array}{r}11 \cdot 3 \\
9 \cdot 3 \\
12 \cdot 1 \\
14 \cdot 0 \\
14 \cdot 1 \\
12 \cdot 3\end{array}$ & $\begin{array}{l}-\overline{-} \\
0.6 \\
1.2 \\
0.8 \\
0.4\end{array}$ \\
\hline Total & 935 & 100 & 702 & 100 & 395 & 100 & $13 \cdot 0$ & $0 \cdot 7$ \\
\hline
\end{tabular}


before 8.0 p.m. It should, therefore, be possible to organize domiciliary services to meet more of their needs.

REFERRING DocToR.-To what extent do attributes of the treating doctor facilitate or hinder admission? It is generally assumed that doctors with good personal relationships with their local hospital staff have less difficulty in arranging admission for their patients than doctors without such personal relationships. This study cannot add any information on that point. But almost 30 per cent. of the doctors of control and MR cases could not be traced in either the published Medical Register or in the Medical Directory. About half of the doctors who could not be traced were working on behalf of a deputizing service. It is probable that a substantial number of the remainder were assistants, locums, and/or recently qualified doctors. This suggests that an undue proportion of doctors who use the EBS service are not established in practices. Among the doctors who could be found in the Register or Directory, there were no significant differences in the dates of qualification and in the clinical medical schools attended. However, because 72 per cent. of the doctors were concerned with only one patient, it is not possible from the data collected to draw any firm conclusions about the characteristics of doctors who use the EBS or to identify any factors relating to the doctor which affect the probability of admission of his patient.

\section{Subsequent History of Patients Referred Back}

The fate of those patients who are not admitted at the time of first referral is obviously of concern. Of the 378 patients referred back by the EBS to their general practitioners and about whom information was available, 235 (62 per cent.) were admitted to hospital and a further seven to a nursing home or residential institution within a week of the first referral. Of these 157 (42 per cent.) were admitted either on the same day or during the next day, and a further 58 (15 per cent.) on the second, third, or fourth day after referral. So that, by the end of the fourth day, 215 (57 per cent.) of the original 378 had been admitted to hospital. The EBS arranged 113 (47 per cent.) of these admissions relating to the index episode of illness, 81 ( 33 per cent.) were arranged by the general practitioner directly contacting the hospital, and 29 (12 per cent.) following domiciliary consultations, and other procedures were adopted in the remaining 19 (8 per cent.). 114 (47 per cent.) of the patients were admitted to hospitals which had previously been approached by the EBS.
Of the 136 patients not admitted to hospital, 33 were considered still to be in need of admission (this represents just under 9 per cent. of the original number referred back), 69 were considered not to need hospital admission, and in 34 cases the question was either not applicable or not answered. These findings suggest that failure to admit a patient at the time of first referral, may create an acute problem, but that the situation is likely, in the majority of cases, to be resolved within a week. This is in no way to belittle the stresses and strains endured by the patient, his family, and his general practitioner during these days of waiting. Eleven of the 33 patients still requiring admission were men and 22 were women; four of the men and eleven of the women were aged 75 years or more. Seven of the 33 patients were suffering from cerebro-vascular accident and five from cancer. These data emphasize the previous findings regarding the influence of age and diagnosis upon emergency admission. It might be argued that these diagnoses are not suggestive of emergencies, but in these cases there had been changes in the medical or social situation which had precipitated an emergency.

Each doctor was asked whether the condition of his patient had changed since the first referral. The condition of 116 (31 per cent.) was unchanged and of 93 (25 per cent.) improved, but 55 (14 per cent.) haof deteriorated, and 38 (10 per cent.) were dead. A further 22 (6 per cent.) had recovered and most of these had not been admitted to hospital. The condition of 54 (14 per cent.) was not known, usually because the patient was in hospital.

DeATHS.-There is no evidence that admission at the time of the first referral would have prevented any of the deaths that occurred. However, this is not the way that the relatives and friends of the deceased are likely to view the failure of admission. Only thirteen of the 38 RB patients who died had been admitted to hospital sometime between the first referral and the time of death, so that 25 patients died at home without being admitted. Of the 38 patients who died, 76 per cent. were referred to the EBS by their own doctor, and 28 of them were 75 years or over, the commonest diagnoses being cerebro-vascular accident (9), pneumonia (8), cancer (7), and cardiac failure (6). Only three patients were under the age of 65 years and they died from cancer (2) and chronic bronchitis (1). Thirteen (34 per cent.) of the deaths occurred either on the day of referral or the next day and another thirteen on the second or third day after first referral. Thus, 68 per cent. of the deaths occurred within 4 days of the first referral to the EBS. 
Social Factors.-Only 54 (14 per cent.) of the patients were living alone, but a further 104 (28 per cent.) were living with a relation or friend who was unable to provide the help required; just over half were living with a relative or friend who was able to give help. Of the 371 general practitioners who replied, 93 ( 25 per cent.) made additional comments about social factors that contributed to the urgency of the need for admission. But these factors, although an important part of the total picture, were seldom the determining factors in the decision to seek hospital admission through the EBS. There had usually been an acute change in the patient's condition.

DomicIliary CARE.-Having failed to obtain admission for his patient, a general practitioner will naturally consider, again, what domiciliary services he might utilize to alleviate the situation. In regard to 126 (33 per cent.) of the 378 patients, the general practitioner had sought the help of the domiciliary services. Consultants attended 22 patients on domiciliary consultations. The district or home nurse was called to seventy patients, a home help to 21 , a private nurse to three, and a "night sitter-in" service to three. Other services (e.g. home-meals, loan equipment) were used in a few cases. Some of the services were, of course, used in conjunction with each other and some were already in use at the time of referral. Some of the general practitioners remarked on the lack of a local night sitter-in service and on the difficulty of mobilizing the home nurse or home help service after normal office hours, and indeed, in regard to the home help service, on the delays that occur between request and service. No marked differences were found between the London boroughs in regard to the utilization of or satisfaction with the domiciliary services, nor between the four regional hospital boards in regard to domiciliary consultations.

\section{Discussion AND ReCOMmendations}

The findings of this survey draw attention to the difficulty of emergency admission to hospital in the London area. During one year, in respect of some 7,000 patients, six or more hospitals had to be approached by the EBS and then a medical referee contacted before admission could be arranged. During the same period almost 400 patients could not be admitted through the EBS at the time of their first referral. There is evidence from the data in this survey and from statements made by general practitioners that many of them use the EBS only after they have made unsuccessful attempts to get their patients admitted to their local hospitals. Thus the position is likely to be understated when only EBS figures are considered. Furthermore, as the EBS is concerned only with emergency admissions, its figures can in no way reflect the real pressure on hospital beds. It is not therefore possible to make any recommendations or calculations about the extra number of beds needed. Indeed, in the light of past experience (Feldstein, 1964), it would be naïve to presume that, if a small number of extra beds were made available in each region, they would be used directly to meet the problem of emergency admissions. This is not to say that there is not a need for extra hospital beds in London; but to suggest that administrative action and clarification of duties may have greater effect on the problem than the allocation of additional beds.

The areas of difficulty revealed in this study are:

(1) Combining efficient use of hospital facilities with flexibility.

(2) Aggravation of the general problem during the first 3 months of the year.

(3) Delay in the admission of women with abortions, of patients of both sexes suffering from cerebrovascular accident, cardiac failure, and terminal cancer, and of older people.

(4) The unwieldy process of mobilizing domiciliary services.

This study has shown that many hospitals admit patients within 48 hours of refusing them. This is not a surprising finding, because given time, a patient in the hospital can be discharged; whereas it would be harsh and inhuman to have discharged that patient without any warning or opportunity for him or his relatives to prepare for his return home. Furthermore, Newell $(1954,1962)$ has calculated that any unit which deals with its own emergency demand, must have available two beds more than the average demand for emergency admissions in order to satisfy the demand in 95 per cent. of requests. Clearly, therefore, demand is more likely and more economically to be met where there is a pooling of emergency admissions; this, Newell suggested, could be achieved by the use of a pre-discharge ward suitable for adult patients of both sexes and all specialties during the last few days of their hospital stay. Zinovieff, Newell, and Hurst (1966) described the first 4 years' experience of such a pre-discharge ward and concluded that the ward did provide valuable flexibility in the number of beds available to the different specialties and sexes at times of peak demand and that most patients did not resent the move to another ward. Experiments on these lines should be tried out in some of the London hospitals. 
Hospital management committees make some effort to meet the demands ensuing from the rise in morbidity during the winter months, by postponing redecoration, re-equipping, and other structural alterations until the summer months, and postponing non-urgent admissions. It might be necessary for some hospitals to have an additional medical ward staffed mainly by part-time nurses and workers which was planned to be open only from January to March. It would be interesting to know, whether, for example, some married or recently retired nurses would be prepared to work for only 3 months in the year. This might be an attractive form of part-time working for some people, and would add to the flexibility of the hospital service.

Of the four diagnostic categories (abortion, cerebro-vascular accident, cardiac failure, and terminal cancer) that are particularly associated with delay in admission, the first raises different issues from the other three. During the year surveyed, the vast majority of applicants with abortions were eventually admitted to hospital. In this respect the experience during the survey showed an improvement over previous years. That there was still some difficulty, however, is shown by the fact that almost one in every eight applicants was admitted via the referee procedure. In view of the immediate hospitalization that these patients require, this finding is disturbing. A few may need elaborate resuscitation, but many will need very little treatment and then only for a few days. In the conurbations, further consideration should be given to a few specialist units for these emergency cases, rather than trying to cope with them in each individual gynaecological department.

The difficulty of the emergency admission of patients suffering from cerebro-vascular accident, cardiac failure, and terminal cancer stems, in part at least, from misunderstandings about the respective roles of the hospitals and of the domiciliary services in the care of these patients. Basically, many of these patients need nursing care and medical supervision. Where the home conditions are suitable, much of this can be managed at home by the use of domiciliary services, although this may deprive patients in the first group of adequate rehabilitation treatment. However, there are some patients in each of these groups who require from the onset of their illness more nursing care and medical treatment than can be given at home. There are others who can be managed at home for a long period of time, but whose condition suddenly changes and so necessitates hospital admission; and yet others whose social situation changes (e.g. illness of the supporting relative) so that they need to be admitted to hospital. As more patients with chronic conditions are treated at home, so will the demand for the "emergency" admission of such patients rise. It is the demand for "routine" admissions that should fall. These facts are well-known and accepted by geriatricians. They are not so well accepted by other consultants. The College of General Practitioners (1965) has stated that "the modern hospital should provide family doctors with nursing care beyond that obtainable at home ... and treatment requiring frequent or personal supervision". Glyn Hughes (1960) considered that "there should be a much greater readiness on the part of medical and lay staff to admit to acute beds those patients entering into the final stage of their illness, who can be regarded as acute in their need for a high standard of nursing care and the ready availability of medical staff to supervise their medical needs, especially the relief of pain". Hospital staff must accept the need to care for these patients and it is suggested that re-admission should be the responsibility of the consultant or his successor who has treated the patient for the causative condition. Subsequent transfer may have to be arranged, but at least the responsibility for admission for a large number of these patients would be defined.

The findings of this survey suggest that the domis ciliary services of the local health authorities are nod used as extensively or as intensively as might have been expected for this group of seriously ill patients awaiting hospital admission. This might be because of lack of information about the services (Anderson and Warren, 1966) or, as some general practitioners commented, because the services cannot be adequately mobilized sufficiently quickly. Cartwright and Marshall (1965) noted that the general practitioners they interviewed complained of the inadequacy of the home nurse and home help service, difficulty in getting a home help quickly, and the lack of "sitters-in". Hockey (1966) studied the domiciliary nursing services in six areas in England and concluded that there was a need for expansion of the home nursing and home help services. Some local health authorities (e.g. Kent C.C., Aberdeen, Portsmouth, and Camden) provide a night-care service in emergencies to help families who are looking after sick or elderly relatives at home. Such services need to be more fully and extensively developed in London, and the arrangements for mobilizing the present services need improving to provide adequate help in emergencies.

\section{SUMMARY}

A study has been made of a sample of all general applications for emergency admission to hospital to $\stackrel{\mathcal{D}}{?}$ the Emergency Bed Service in London between April 1, 0 1965, and March 31, 1966. All patients who could 
not be admitted at the time of the first request have been followed-up by means of a postal questionnaire to their general practitioners. A total of 2,032 requests for admission was examined. Out of the 395 patients who could not be admitted, information about 378 was obtained. Almost two-thirds of these patients were admitted to hospital within a week of the first referral to the EBS, and in about half of this number the arrangements were made through the EBS. About 10 per cent. of the patients died, but some of these deaths occurred in hospital.

Evidence is presented that older people in general and patients suffering from abortions, cerebrovascular accident, cardiac failure, and terminal cancer experience difficulty in obtaining emergency admission. The difficulties are aggravated during the months of January, February, and March.

It is recommended that hospitals should experiment with pre-discharge wards, and that a few special units for women with abortions should be established in the metropolitan area. Hospital staff must be prepared to accept, more readily, patients with acute exacerbations of chronic conditions. The domiciliary services of the local health authority should include a night sitter-in service, and the services should be so organized as to be able to respond to emergency calls.

The authors wish to thank the Ministry of Health for a grant to cover the additional costs of this survey, Dr J. M. G. Wilson for suggesting the study, Mrs G. Cartwright, O.B.E., for considerable help in coding the information, Dr G. F. Abercrombie, Dr M. A. Heasman, Dr J. P. Horder, Prof. W. S. Walton, and many others for their help and advice, the staff of the EBS for their co-operation, and all the general practitioners who supplied information about their patients. In conclusion, reference must be made to the esteem and gratitude that general practitioners have for the Emergency Bed Service. Many commented on the excellence of the service. In the words of one of them, "I find the EBS an invaluable help".

\section{REFERENCES}

Abercrombie, G. F. (1951). Lancet, 2, 1175. (1956). Ibid., 2, 1039. (1959). Ibid., 2, 398. (1961). Proc. roy. Soc. Med., 54, 285.

Anderson, J. A. D., and Warren, E. A. (1966). Med. Offr, 116, 333.

Cartwright, A. (1964). "Human Relations and Hospital Care". Routledge and Kegan Paul, London. and Marshall, R. (1965). Med. Care, 3, 69.

College of General Practitioners (1965). "Reports from General Practice. II. Present State and Future Needs". Feldstein, M. S. (1964). Brit. med. J., 2, 561.

Gibson, J. R., Hughes, T. L., and Broughton, A. V. L. (1958). Med. Offr, 99, 117.

Hockey, L. (1966). "Feeling the Pulse: A Survey of District Nursing in Six Areas". Queen's Institute of District Nursing, London.

Hughes, H. L. Glyn (1960). "Peace at the Last-A Survey of Terminal Care in the United Kingdom". Calouste Gulbenkian Foundation, London.

King Edward's Hospital Fund (1965). "Emergency Bed Service, 27th Annual Report for the year ending March 31, 1965". (1966). Idem, 28th Annual Report.

Ministry of Health (1965). "On the State of the Public Health". Annual Report of the Chief Medical Officer. H.M.S.O., London.

Newell, D. J. (1954). Brit. J. prev. soc. Med., 8, 77. (1962). Hospital (Lond.), 58, 13.

Zinovieff, A., Newell, D. J., and Hunt, L. W. (1966). Lancet, 2, 1293. 